\title{
Substantial increase of heat requirement for maturity of early rice due to extension of reproductive rather vegetative growth period in China
}

Yaru Zhang ( $\square$ zhangyaru@mail.bnu.edu.cn )

Beijing Normal University

Yahui Guo

Shuxin Wang

Wenxiang Wu

Yongshuo H. Fu

https://orcid.org/0000-0002-9761-5292

\section{Research Article}

Keywords: climate change, early rice, heat requirement, phenology

Posted Date: March 7th, 2022

DOI: https://doi.org/10.21203/rs.3.rs-1348174/v1

License: (9) This work is licensed under a Creative Commons Attribution 4.0 International License.

Read Full License 


\section{Abstract}

Climate change has affects crop phenology, leading to changes in agriculture productivity. Previous studies usually take phenology and agriculture as two parallel aspects that climate change would exert influence on, rarely taking the impacts of phenology on agriculture productivity into account. In this study, trial data on early rice phenology and in situ meteorological data at 48 national agro-meteorological experiment stations during 1981 to 2010 were used to investigate the variability of heat accumulation and its driving factors. Using linear function, piecewise function, and sigmoidal function three methods, shifts in heat accumulation during vegetative growth period, reproductive growth period, and the whole growth period were calculated. Then, the correlations between changes in Growing Degree Days (GDD) and (i) three growth durations and (ii) climatic variables were assessed. Our findings indicated that the heat accumulation for early rice was significantly increased by $20 \%$ during the whole growth period (WGP), which was mainly attributed to the increase of GDD during the reproductive growth period (RGP), while GDD during the vegetative growth period (VGP) showed no significant changes. Changes of early rice GDD were closely related to the variations of the RGP duration, which was prolonged by 6.08 day/decade, while VGP duration did not change significantly. Both simple correlation and partial correlation analyses indicated that the positive impacts of growth duration played a dominant role in determining GDD variability, with the average coefficients of 0.91 during VGP, 0.97 during RGP, and 0.93 during WGP, respectively, while temperature played a secondary role. Our studies revealed the dynamics of individual-specific heat accumulation over the past three decades, and emphasized the importance of phenology to agriculture productivity. Therefore, changes in crop phenology should be sufficiently taken into consideration for the better understanding of agriculture dynamics under climate change, and for improving the accuracy of crop model simulation.

\section{Introduction}

Climate change including variations in temperature, precipitation and solar radiation have significantly affected the phenology, the growth duration, and thus the crop yield, although large uncertainties remain in terms of impact magnitude, spatial pattern and mechanisms (Ortiz et al., 2008; Tao et al., 2013; Y. Chen et al., 2018). The ongoing increase in carbon dioxide would result in further global warming. Since 1960, the annual average temperature has increased by $1.2^{\circ} \mathrm{C}$ in China, and is estimated to continuously increase by 1 to $5^{\circ} \mathrm{C}$ by 2100 (Solomon, S. et al., 2007; Piao et al., 2010). At the same time, the drier regions in North China are receiving less precipitation, while the wetter regions in South China are experiencing more rainfall, which directly induce a more significant spatial difference of precipitation (Guo et al., 2020; Xin et al., 2020). Moreover, the climate extremes, especially drought and flood, appeared frequently in the past few decades, exerting further ecological and agricultural pressure (Deryng et al., 2014; Hatfield and Prueger, 2015; R. Chen et al., 2018). With the increase of greenhouse emissions, the trend of climate warming will continue in the coming decades, and will be more prominent in cultivated areas (Lobell et al., 2011), which would bring higher risk for future regional food security (Ainsworth et al., 2008; Leakey, 2009; Vanuytrecht et al., 2012; Pugh et al., 2016). The heat accumulation during growth 
period, which is usually characterized by Growing Degree Days (GDD), is closely controlled by climate change, directly related to the energy needs for crop development, and further exert a significant influence on crop yield. Besides, the nitrogen deficiency, water shortage, and photoperiod requirements should not be ignored for vegetation development. Researches using either environment-controlled experiments (Ottman et al., 2012), or historical records (Lobell et al., 2011; Tao et al., 2014), or crop model simulations (Porter et al., 2015; Asseng et al., 2013) have documented that global warming would shorten the crop growth duration and then reduce crop yields (Porter et al., 2015). However, for area with insufficient heat such as temperate areas, raising temperature could complement heat defect and thus lead to the increase of yield (Tao et al., 2013; Tao et al., 2014; Zhang et al., 2014). Therefore, given the significance of GDD to agricultural productivity and its regional uncertainty, understanding the GDD variations and their driving factors is crucial to agriculture monitoring and management (Yin et al., 2019).

Phenology determines the crop growth period. For the whole life cycle of early rice, growth period begins in spring with the photosynthesis starting when temperature and solar radiation increase up to a certain threshold (spring phenology, transplanting for rice), and terminate in autumn as photosynthesis ceases when temperature and solar radiation decrease (autumn phenology, maturity for rice) (Kimball et al., 2004; Euskirchen et al., 2006). As the metric of heat requirement for growth and development, GDD is controlled by both the growth duration and temperature, and is mainly affected by both phenology and climate change (Deng et al., 2018). Previous studies indicated that GDD is positively related to the seedling recruitment in the context of warming near the boreal forest (Miller et al., 2017). The GDD of agriculture system, however, is relatively complex due to the mixed effects by both climatic and agronomic factors, which remains great uncertainty under changing climate (Hildén et al., 2005; Estrella et al., 2007). For example, an increase in daily atmospheric temperature leads to more rapid increase in degree days and hasten maturity, finally resulting in lowered biomass and decreased wheat yield (Zhao et al., 2007; Hatfield and Prueger, 2015; Aslam et al., 2017; Prasad et al., 2017). In the U.S. Corn Belt, after removed the effects of cultivar shift, the number of GDD needed for corn progress was declined, and the yields would have been 12.6 bu ac $^{-1}$ lower around 2005 (Sacks and Kucharik, 2011). However, studies focusing on GDD of early rice, one of the most widely planted crops around the world, are scarce. Besides, GDD in agricultural researches were usually used to reflect regional heat resources, while individualspecific actual heat accumulation during growth period is always ignored, and therefore need to be discussed. Since cultivated area accounts for about $12 \%$ of the surface area (Ramankutty and Foley, 1998), shifts in crop growth period and GDD would exert great influence on water and carbon fluxes, and thus regional and even global climate (White et al., 1999; Baptist and Choler, 2008; Wu et al., 2012; Tao et al., 2012). Furthermore, GDD directly impose influence on crop yield and productivity, which consequently bear great significance for food security and economic stability (Challinor et al., 2010; Asseng et al., 2011; Tao et al., 2012; Licker et al., 2013). Therefore, in this study, we choose early rice, one of the most important part of agriculture in China, which is directly related to national economy and people's livelihood, to investigate the variability of heat accumulation under climate change, and its driving factors. 
Crop GDD is mainly regulated by both temperature and growth duration. On the one hand, climate change and agricultural measures directly affect the heat accumulations of crop by changing the temperatures during growth period; on the other hand, they induce shifts in phenology, which influences the timing and duration of a photosynthetically active canopy and changes of heat accumulation during growth period ensued (Keeling et al., 1996; Myneni et al., 1997). In this analysis, based on in situ agrometeorological experimental data of early rice across 1981 to 2010 in China, we discuss the main factors affecting GDD and its influencing mechanism for early rice. The primary objectives of this study were: (1) to explore the changes of phenological dates and growing season over the past three decades, (2) to investigate the tempo-spatial patterns of GDD changes during each of the growing periods, (3) to identify the relationships between GDD and phenological dates using partial correlation analyses, (4) to determine the main factors and mechanisms leading to changes in heat accumulations for each of the growing periods.

\section{Materials And Methods}

\subsection{Study area and datasets}

In this analysis, South China was selected as the study area. Its latitudes range from $21^{\circ} \mathrm{N}$ to $31^{\circ} \mathrm{N}$ and longitudes from $106^{\circ} \mathrm{E}$ to $121^{\circ} \mathrm{E}$, which is mainly dominated by a subtropical monsoon climate regime. The annual precipitation ranges from $1000 \mathrm{~mm}$ to $1500 \mathrm{~mm}$, rained mainly in summer; the annual average temperature is $12^{\circ} \mathrm{C}-18^{\circ} \mathrm{C}$, with annual cumulative temperature being around $4500^{\circ} \mathrm{C}-8000^{\circ} \mathrm{C}$. Administratively, South China includes Guangdong, Fujian, Zhejiang, Jiangxi and other provinces, and is the major rice production region in China, whose typical cropping systems is double rice cultivation (i.e., rotation between early rice and late rice). In this study, we chose early rice that is usually transplanted around April and mature around June as the research subject.

Dataset of phenology for early rice were obtained from China Meteorological Data Service Centre (http://data.cma.cn/en/?r=site/index), and stations with consecutive agriculture experimental data were selected to ensure the analysis reliability and precision. The dates were recorded as Day of Year (DOY) for more than 15 years during 1981 to 2010. As a result, 1106 records at 48 sites were collected in this study (Fig. 1).

In situ meteorological dataset including daily average air temperature $\left({ }^{\circ} \mathrm{C}\right)$, cumulative precipitation $(\mathrm{mm})$ and cumulative sunshine hours (h) were downloaded from the China Meteorological Data Sharing Service System (http://data.cma.cn/). These data were measured, recorded and collected following a strict set of data quality control practices by the China Meteorological Administration (CMA) (China Meteorological Administration, 1993).

\subsection{Method}

\subsubsection{Growth period and relevant time period}


For the 48 sites involved in this study, we first defined three growth periods as the time intervals between multi-year average three phenological dates (transplanting, heading, maturity). Such three phenological dates were selected to divide vegetation development into three growth stages, i.e., vegetative growth period (from transplanting to heading, VGP), reproductive growth period (from heading to maturity, RGP) and the whole growth period (from transplanting to maturity, WGP). The duration of growth period is the growing season length (GSL), which is a direct factor that determines the GDD. When considering the meteorological influencing factors, we calculated the variables during a period before phenology, which is called "preseason". Preseason before transplanting was defined as the period (length ranges from 15 to 120 days with 15-day steps) with highest absolute partial correlation coefficient between the date of transplanting and daily average air temperature, during which the mean temperature is closely related to transplanting dates. To avoid the error caused by autocorrelation, the growth periods as well as the preseason before transplanting were fixed at specific sites. Then we calculated the climatic variables during the fixed preseason and growth periods at each site, including average air temperature, cumulative precipitation and cumulative sunshine hours.

\subsubsection{GDD calculation}

GDD, serving as the metrics of heat accumulations during growth periods, was defined as the sum of daily mean air temperature above a threshold by three methods (linear function, piecewise function, sigmoidal function), following previous studies (Fu et al., 2019).

1. Linear function. GDD was calculated as the accumulated daily average air temperature above a threshold of $5^{\circ} \mathrm{C}$.

$$
\operatorname{GDD}\left(\mathrm{x}_{\mathrm{t}}\right)=\left\{\begin{array}{c}
\text { 0if }_{\mathrm{t}} \leq 5 \\
\sum_{\mathrm{t} 2}^{\mathrm{t} 3}\left(\mathrm{x}_{\mathrm{t}}-5\right) \text { if }_{\mathrm{t}} \geq 5
\end{array}\right.
$$

2. Piecewise function. GDD was calculated as the linear function when daily mean air temperature was between $5^{\circ} \mathrm{C}$ to $10^{\circ} \mathrm{C}$, and the accumulated value was fixed when daily mean air temperature was above $10^{\circ} \mathrm{C}$.

$$
\operatorname{GDD}\left(\mathrm{x}_{\mathrm{t}}\right)=\left\{\begin{array}{c}
0 \text { if }_{\mathrm{t}}<5 \\
\sum_{\mathrm{t} 2}^{\mathrm{t} 3}\left(\mathrm{x}_{\mathrm{t}}-5\right) \text { if5 } \leq \mathrm{x}_{\mathrm{t}} \leq 15 \\
\sum_{\mathrm{t} 2}^{\mathrm{t} 3} 10 \text { if } 5 \leq \mathrm{x}_{\mathrm{t}} \leq 15
\end{array}\right.
$$

3. Sigmoidal function. GDD was calculated by sigmoidal function: 


$$
\operatorname{GDD}\left(\mathrm{x}_{\mathrm{t}}\right)=\left\{\begin{array}{c}
0 \text { if }_{\mathrm{t}}<0 \\
\frac{28.4}{1+\mathrm{e}^{-0.185\left(\mathrm{x}_{\mathrm{t}}-18.4\right)}} \text { if } \mathrm{x}_{\mathrm{t}} \geq 0
\end{array}\right.
$$

$\mathrm{x}_{\mathrm{t}}$ in the functions is the daily mean air temperature during growing season and $t 2, \mathrm{t} 3$ represent the start and end of the growing season, respectively.

\subsubsection{Trend and impact factor analysis}

We performed the ordinary least squares (OLS) regression (Kilmer and Rodríguez, 2017) to figure out the temporal trends of phenological events, climatic variables and GDD during the growth periods. The OLS regressions were applied for each site to construct histogram of the coefficients and the yearly average values of all stations along the time series were also regressed to verify the accuracy of the temporal trends. Both the average values of the histogram and slopes of multi-site variations along time series were used as the indicators of the trend.

Simple correlation analysis and partial correlation analysis were applied to determine the main factors that closely related to the date of phenological events and the heat accumulations during growth periods for each site. To remove the confounding factors, detrended fluctuation method was applied in all variables before partial correlation analyses. The coefficients of simple correlation and partial correlation analyses were used as the metrics to assess the effects of the climatic factors on phenological events and heat accumulations during the growth periods. The data for each site in each year was calculated in MATLAB.

\section{Results}

\subsection{Climate trends during the growth periods}

During 1981-2010, few significant changes of temperature were detected during VGP, RGP or WGP (Fig. 2a). Although the mean air temperature across all 48 sites has increased by $0.28 \pm 0.03^{\circ} \mathrm{C} /$ decade (mean \pm S.E.), $0.35 \pm 0.06^{\circ} \mathrm{C} /$ decade (mean \pm S.E.) and $0.31 \pm 0.04^{\circ} \mathrm{C} /$ decade (mean \pm S.E.) during VGP, RGP and WGP, respectively, none of them were significant (Fig. 2b, c, d, $P>0.05$ ). Meanwhile, the average air temperature at most sites were increased but only $17 \%$ of them were significant $(P<0.05)$. Similar trends were also found in cumulative precipitation, with the increases of $12.09 \pm 6.01 \mathrm{~mm} /$ decade (mean \pm S.E.), $7.78 \pm 6.34 \mathrm{~mm} /$ decade (mean \pm S.E.) and $18.84 \pm 8.18 \mathrm{~mm} /$ decade (mean \pm S.E.) over VGP, RGP and WGP, respectively, but no one was significant (Fig. $2 f, g, h, P>0.05$ ). Regression analyses at each site clearly indicated that the proportion of sites with positive and negative rates were very similar, and few of them were significant. As for cumulative sunshine hours, although the fitting trends were decreasing, there were no significant changes $(P>0.05)$ during VGP, RGP or WGP; similar results were found for all the sites (Fig. 2j, k, I). Therefore, regardless of vegetative growth period, reproductive growth period, or 
throughout the whole growth period, the climatic conditions including the mean air temperature, cumulative precipitation and cumulative sunshine hours of early rice in South China haven't changed significantly during each of the growth period.

\subsection{Changes of early rice phenology during 1981-2010}

The average of transplanting, heading and maturity dates were calculated across 48 agrometeorological stations in the major early rice production regions. The corresponding DOY were $113 \pm 15$ (mean \pm 1 SD), $167 \pm 15$ (mean \pm 1 SD) and $197 \pm 16$ (mean \pm 1 SD), respectively (Fig. 3a). During 1981-2010, the transplanting date was significantly advanced by 3.88 day/decade $(P<0.001)$, which is consistent with the trend towards earlier heading date of 3.82 day/decade $(P<0.001)$. In contrast, the maturity date was significantly delayed by 2.27 day/decade (Fig. 3b, $\mathrm{P}<0.001$ ). As a result, there was no significant change of the length of VGP with the synchronization between transplanting and heading dates, while the length of RGP was prolonged by 6.08 day/decade, thus making the major contributions to the increased length of WGP (6.15 day/decade).

\subsection{Temporal characteristics on trends of heat accumulations during growing seasons}

Results calculated by linear function model showed that during 1981-2010, heat accumulations during WGP increased notably by $144.64^{\circ} \mathrm{C} /$ decade $(P<0.001)$, which makes a main contribution to the increase of GDD during RGP with the rate of $152.63^{\circ} \mathrm{C} /$ decade $(P<0.001$; Fig. $4 \mathrm{a}$, b). Significant increase in GDD were found at more than $80 \%$ sites during RGP. Across all sites, GDD during RGP has been raised by approximately $430^{\circ} \mathrm{C}$, which is 1.86 times of the average value during the period from 1981 to 2010 ;GDD during WGP has been raised by approximately $410^{\circ} \mathrm{C}$, which is 1.27 times of the average value during the from 1981 to 2010. Heat accumulations during VGP, however, reported no significant changes $(P=0.52)$ during the study period. Similar relationship among GDD during VGP, RGP and WGP were also found with the piecewise function and sigmoidal function. Such analysis further indicated that GDD during VGP showed no significant changes, while GDD during RGP increased significantly, which directly lead to a significant increase of GDD during WGP (Fig. 4c, d, e, f).

\subsection{Relationships between GDD and factors}

GSL and climatic variables (i.e., mean air temperature, cumulative precipitation, cumulative sunshine hours) were considered as the main influencing factors for the accumulations of heat. Therefore, after removing the variation explained by climatic factors, we found that GSL was strongly positively associated with GDD during each of the growth period (Fig. 5). Furthermore, the partial correlation coefficients for the relationships between GDD and GSL were much higher than those of the relationships between GDD and climatic variables, suggesting that the heat accumulations might been regulated mainly by the GSL.

GDD were positively correlated with GSL $(P<0.05)$ during each of the growth periods across all sites with the average coefficients being $0.9,1.0$, and 0.9 , respectively. As for climatic factors, the average of the 
coefficient between GDD and mean air temperature during VGP was calculated to be 0.6 using partial correlation analysis, of which most of the correlations are positive (52\%) across all sites, and $8 \%$ of those were significant. Similar results were found during RGP and WGP. Their average coefficients were 0.5 ( $77 \%$ were positive, $11 \%$ of those were significant) and 0.7 ( $79 \%$ were positive, $26 \%$ of those were significant), respectively, with significant proportions being larger than that during VGP. However, after removing the effects of both GSL and temperature, no apparent correlations between GDD and cumulative precipitation or cumulative sunshine hours during each of the three growth periods (VGP, RGP and WGP) were found; the proportions of negative and positive were closely similar and few were significant. In conclusion, we found that GDD during all growth periods were mainly regulated by the length of growing season, while temperature played a secondary role. Few significant correlations were found for the relationships between GDD and cumulative precipitation or cumulative sunshine hours during all growth periods. Since GDD calculated by three methods showed similar performance, we only displayed the results with linear function here. Similar results were obtained by simple correlation analysis, and were displayed in Appendices (Fig. A.1).

\section{Discussion}

GDD is directly affected by growth duration and ambient temperature, while the growth duration itself is determined by phenology and regulated by climatic factors including air temperature, precipitation and sunshine hours (Chen and Gong, 2021). Thus GDD, phenology and climatic factors are closely related and mutually restricted (Zhu et al., 2018; Kukal and Irmak, 2018). Previous studies have found that increase in daily air temperature leads to more rapid increase of degree days and hastens maturity, finally results in lowered biomass and decreased yield in both wheat and corn (Zhao et al., 2007; Hatfield and Prueger, 2015; Aslam et al., 2017; Prasad et al., 2017; Sacks and Kucharik, 2011), which is consistent with what we found about the relationship between temperature and GDD. To better understand the variations of GDD throughout the growing season, in this study, trial data on early rice phenology and meteorology at 48 national agro-meteorological experiment stations were used to investigate GDD variability during VGP, RGP and WGP, respectively. A significant increase of GDD from transplanting to maturity were detected, which was consistent with research findings by Xu et al., 2016 and Deng et al., 2018. Furthermore, both simple correlation and partial correlation analyses showed that GDD was mainly regulated by both growth duration and ambient temperature, of which growth duration played a key dominant role. Whether during VGP, RGP or VGP, the temporal variability of GDD is synchronous with growth duration. Since growth duration is directly determined by crop phenology, it can be reasonably inferred that phenology played a key role in determining heat accumulation during growth period, consequently exerting significant impact on crop yield (Xu et al., 2018; Li et al., 2020). Previous studies on crop GDD mainly focused on the heat accumulations during thermal growing season, which is fixed by a base temperature and represents regional heat resources (Sikder, 1970; Ram et al., 2012; Zhou and Wang, 2018). By comparing the regional heat resources with actual heat requirement, we can infer the appropriate planting regions and planting time for crops, also to predict the possible distribution of the crops under future climate scenario, further to provide reasonable agricultural management measures 
(Kukal and Irmak, 2018). However, in this analysis, three methods (linear function, piecewise function, sigmoidal function) were used to calculate the individual-specific GDD during each of the growth period, which reflects the actual heat accumulation (requirement), rather than heat resources on regional level. Moreover, detrended fluctuation method was applied to eliminate confounding factors, and helped to better reveal the mechanism leading to GDD variability.

After dividing the whole growth period into vegetative growth and reproductive growth period, we found that GDD during WGP has increased by $20 \%$ since 1980 , in which the increase of GDD during RGP played a dominant role, while no significant changes were found of GDD during VGP, which should be attributed to the synchronous advance of transplanting and heading. The advancing trends of the transplanting and heading were commonly investigated for early rice (Tao et al., 2013; Zhao et al., 2016). However, the characteristic of maturity we investigated was not consistent with previous studies, which indicated that the maturity date was delayed instead of being advanced by 2.27 days per decade. The disparity between studies may be attributed to the differences of study region and study period. In summary, it indicated that early rice might tend to allocate more time to reproduction than to growth, to invest more energy and thus be more competitive during RGP (Liu et al., 2021). We proposed two possibilities to explain the phenomenon: first, in response to population growth, the cultivar of early rice was switched to variety with higher yield (Aggarwal and Mall, 2002), which needs longer RGP to accumulate heat and energy for growth and development. secondly, the application of agricultural management, such as spraying pesticide that was used to increase crop production, may extend the growing season length and sequentially increased the GDD requirement (Yang et al., 2015).

Previous studies always take phenology and agriculture as two parallel aspects that climate change would exert influence on, while seldom take the impacts of phenology on agriculture productivity into account. In this analysis, phenology is regarded as a factor affecting agriculture productivity, and GDD is regarded as an index closely related to the level of crop yield. Through discussing the relationship between crop phenology and GDD, we could better understand the crop responses to climate change. It is beneficial to formulate more reasonable management measures for agriculture ecosystem under ongoing climate change (Shahzad et al., 2021).

In GDD-driven crop models, GDD is generally regarded as a constant, ignoring the changes of heat demand in reality (Lobell et al., 2011; Xu et al., 2018; Hussain et al., 2018). According to our research, the actual heat accumulation is mainly affected by growth duration, which is dominated by phenology. As a result, we supposed that traditional crop models that only consider climatic and environmental factors as input variables, while ignoring the effects that phenology imposed on GDD may make the simulation result less reliable and precise (Tao et al., 2009).

Our analysis emphasized the importance of phenology to GDD during growth period, and took the impacts of cultivar shift and agricultural management into consideration. However, there are still limitations in our analysis that need to be pointed out. For example, only early rice was involved, while changes of other rice varieties are still unknow. Besides, the internal mechanism between phenology and 
heat requirement has not been fully explained, thus further experiments are needed to test related hypotheses. Hence, future studies are supposed to further explore the internal relations between phenology and heat accumulations, and input phenology as empirical parameters to improve the accuracy of crop model simulation.

\section{Conclusions}

In this study, we investigated the temporal trends of phenological events (transplanting, heading and maturity dates) and growth periods as well as the changes of thermal GDD of early rice at 48 sites across South China during the period 1981-2010. The advanced transplanting date and delayed maturity date have both significantly lengthened the growing season, which could mainly attribute to the increase in the length of RGP. Considering that climatic factors during each of the growth period did not significantly change during the past few decades, changes in the advent of phenological dates were owed much to two factors: agricultural management and legacy effects from preceding phenology. The temporal variability of GDD was quite different in VGP and RGP, respectively. In general, changes in GDD were basically consistent with the changes in the length of growing season, and GDD during VGP showed no significant changing signal but GDD during RGP has increased significantly across almost all sites, which suggested that the increase in GDD mainly attributed to the increase of the growing season length. Thus, both climatic factors and growing season length should be taken into consideration in assessing the changes of heat accumulations, and the length of growing season is mainly determined by the dates of phenological events. Therefore, the effects of phenology on heat accumulations and even on the crop yield should also be well explored.

\section{Declarations}

\section{Acknowledgement}

This study was supported by the National Science Fund for Distinguished Young Scholars (grant no. 42025101) and General Program (grant no. 31770516), the Higher Education Discipline Innovation Project (111 Project, rant no. B18006).

\section{Author Declarations}

\section{Funding}

This study was supported by the National Science Fund for Distinguished Young Scholars (grant no. 42025101) and General Program (grant no. 31770516), the Higher Education Discipline Innovation Project (111 Project, rant no. B18006).

\section{Conflicts of interest}


The authors declare that they have no known competing financial interests or personal relationships that could have appeared to influence the work reported in this paper.

\section{Ethics approval}

No animal studies are presented in this manuscript.

No human studies are presented in this manuscript.

No potentially identifiable human images or data is presented in this study.

\section{Consent for publication}

Not applicable.

\section{Data availability}

The original dataset presented in the study are included in the article material, further inquiries can be directed to the corresponding author/s.

\section{Code availability}

Code inquires can be directed to the corresponding author/s.

\section{Authors' contributions}

Yongshuo H.Fu and Wenxiang Wu contributed to the conception of the study; Yaru Zhang performed the data analyses and wrote the manuscript; Yahui Guo and Shuxin Wang helped perform the analysis with constructive discussions.

\section{References}

1. Aggarwal PK, Mall RK (2002) Climate change and rice yields in diverse agro-environments of India. II. Effect of uncertainties in scenarios and crop models on impact assessment. Clim Change. https://doi.org/10.1023/A:1013714506779

2. Ainsworth EA, Leakey ADB, Ort DR, Long SP (2008) FACE-ing the facts: Inconsistencies and interdependence among field, chamber and modeling studies of elevated [CO2] impacts on crop yield and food supply. New Phytol. https://doi.org/10.1111/j.1469-8137.2008.02500.x

3. Aslam MA, Ahmed M, Stöckle CO, Higgins SS, ul Hassan F, Hayat R (2017) Can growing degree days and photoperiod predict spring wheat phenology? Front. Environ Sci 5. https://doi.org/10.3389/fenvs.2017.00057

4. Asseng S, Ewert F, Rosenzweig C, Jones JW, Hatfield JL, Ruane AC, Boote KJ, Thorburn PJ, Rötter RP, Cammarano D, Brisson N, Basso B, Martre P, Aggarwal PK, Angulo C, Bertuzzi P, Biernath C, Challinor AJ, Doltra J, Gayler S, Goldberg R, Grant R, Heng L, Hooker J, Hunt LA, Ingwersen J, Izaurralde RC, 
Kersebaum KC, Müller C, Kumar N, Nendel S, O’Leary C, Olesen G, Osborne JE, Palosuo TM, Priesack T, Ripoche E, Semenov D, Shcherbak MA, Steduto I, Stöckle P, Stratonovitch C, Streck P, Supit T, Tao I, Travasso F, Waha M, Wallach K, White D, Williams JW, Wolf JR, J (2013) Uncertainty in simulating wheat yields under climate change. Nat. Clim. Chang. 3 https://doi.org/10.1038/nclimate1916

5. Asseng S, Foster I, Turner NC (2011) The impact of temperature variability on wheat yields. Glob Chang Biol. https://doi.org/10.1111/j.1365-2486.2010.02262.x

6. Baptist F, Choler P (2008) A simulation of the importance of length of growing season and canopy functional properties on the seasonal gross primary production of temperate alpine meadows. Ann Bot. https://doi.org/10.1093/aob/mcm318

7. Challinor AJ, Simelton ES, Fraser EDG, Hemming D, Collins M (2010) Increased crop failure due to climate change: Assessing adaptation options using models and socio-economic data for wheat in China. Environ Res Lett. https://doi.org/10.1088/1748-9326/5/3/034012

8. Chen R, Wen Z, Lu R (2018) Interdecadal change on the relationship between the mid-summer temperature in South China and atmospheric circulation and sea surface temperature. Clim Dyn 51. https://doi.org/10.1007/s00382-017-4002-5

9. Chen S, Gong B (2021) Response and adaptation of agriculture to climate change: Evidence from China. J Dev Econ 148:102557. https://doi.org/10.1016/j.jdeveco.2020.102557

10. Chen Y, Zhang Z, Tao F (2018) Impacts of climate change and climate extremes on major crops productivity in China at a global warming of 1.5 and $2.0^{\circ} \mathrm{C}$. Earth Syst Dyn 9. https://doi.org/10.5194/esd-9-543-2018

11. Deng H, Yin Y, Wu S (2018) Divergent responses of thermal growing degree-days and season to projected warming over China. Int J Climatol. https://doi.org/10.1002/joc.5766

12. Deryng D, Conway D, Ramankutty N, Price J, Warren R (2014) Global crop yield response to extreme heat stress under multiple climate change futures. Environ Res Lett 9. https://doi.org/10.1088/17489326/9/3/034011

13. Estrella N, Sparks TH, Menzel A (2007) Trends and temperature response in the phenology of crops in Germany. Glob Chang Biol 13:1737-1747. https://doi.org/10.1111/j.1365-2486.2007.01374.x

14. Euskirchen ES, McGuire AD, Kicklighter DW, Zhuang Q, Clein JS, Dargaville RJ, Dye DG, Kimball JS, McDonald KC, Melillo JM, Romanovsky VE, Smith NV (2006) Importance of recent shifts in soil thermal dynamics on growing season length, productivity, and carbon sequestration in terrestrial high-latitude ecosystems. Glob Chang Biol. https://doi.org/10.1111/j.1365-2486.2006.01113.x

15. Fu YH, Piao S, Zhou X, Geng X, Hao F, Vitasse Y, Janssens IA (2019) Short photoperiod reduces the temperature sensitivity of leaf-out in saplings of Fagus sylvatica but not in horse chestnut. Glob Chang Biol. https://doi.org/10.1111/gcb.14599

16. Guo B, Zhang J, Meng X, Xu T, Song Y (2020) Long-term spatio-temporal precipitation variations in China with precipitation surface interpolated by ANUSPLIN. Sci Rep 10. https://doi.org/10.1038/s41598-019-57078-3 
17. Hatfield JL, Prueger JH (2015) Temperature extremes: Effect on plant growth and development. Weather Clim Extrem 10:4-10. https://doi.org/10.1016/j.wace.2015.08.001

18. Hildén M, Lehtonen H, Bärlund I, Hakala K, Kaukoranta T, Tattari S (2005) The practice and process of adaptation in Finnish agriculture. Finnish Environ Inst Mimeogr 335:335(Suomen ympäristökeskuksen Monist

19. Hussain J, Khaliq T, Ahmad A, Akhtar J (2018) Performance of four crop model for simulations of wheat phenology, leaf growth, biomass and yield across planting dates. PLoS ONE 13:1-14. https://doi.org/10.1371/journal.pone.0197546

20. Keeling CD, Chin JFS, Whorf TP (1996) Increased activity of northern vegetation inferred from atmospheric CO2 measurements. Nature 382. https://doi.org/10.1038/382146a0

21. Kilmer JT, Rodríguez RL (2017) Ordinary least squares regression is indicated for studies of allometry. J Evol Biol 30:4-12. https://doi.org/10.1111/jeb.12986

22. Kimball JS, McDonald KC, Running SW, Frolking SE (2004) Satellite radar remote sensing of seasonal growing seasons for boreal and subalpine evergreen forests. Remote Sens Environ. https://doi.org/10.1016/j.rse.2004.01.002

23. Kukal MS, Irmak S (2018) U.S. Agro-Climate in 20th Century: Growing Degree Days, First and Last Frost, Growing Season Length, and Impacts on Crop Yields. Sci Rep 8:1-14. https://doi.org/10.1038/s41598-018-25212-2

24. Leakey ADB (2009) Rising atmospheric carbon dioxide concentration and the future of $C 4$ crops for food and fuel. Proc. R. Soc. B Biol. Sci. https://doi.org/10.1098/rspb.2008.1517

25. Li Y, Hou R, Tao F (2020) Interactive effects of different warming levels and tillage managements on winter wheat growth, physiological processes, grain yield and quality in the North China Plain. Agric Ecosyst Environ 295:106923. https://doi.org/10.1016/j.agee.2020.106923

26. Licker R, Kucharik CJ, Doré T, Lindeman MJ, Makowski D (2013) Climatic impacts on winter wheat yields in Picardy, France and Rostov, Russia: 1973-2010. Agric. For. Meteorol. https://doi.org/10.1016/j.agrformet.2013.02.010

27. Liu H, Lu C, Wang S, Ren F, Wang H (2021) Climate warming extends growing season but not reproductive phase of terrestrial plants. 950-960. https://doi.org/10.1111/geb.13269

28. Lobell DB, Schlenker W, Costa-Roberts J (2011) Climate trends and global crop production since 1980. Science (80-.). 333:616-620. https://doi.org/10.1126/science.1204531

29. Miller AE, Wilson TL, Sherriff RL, Walton J (2017) Warming drives a front of white spruce establishment near western treeline. Alaska Glob Chang Biol 23. https://doi.org/10.1111/gcb.13814

30. Myneni RB, Keeling CD, Tucker CJ, Asrar G, Nemani RR (1997) Increased plant growth in the northern high latitudes from 1981 to 1991. Nature. https://doi.org/10.1038/386698a0

31. Ortiz R, Sayre KD, Govaerts B, Gupta R, Subbarao GV, Ban T, Hodson D, Dixon JM, Iván OrtizMonasterio J, Reynolds M (2008) Climate change: Can wheat beat the heat? Agric. Ecosyst Environ. https://doi.org/10.1016/j.agee.2008.01.019 
32. Ottman MJ, Kimball BA, White JW, Wall GW (2012) Wheat growth response to increased temperature from varied planting dates and supplemental infrared heating. Agron J 104.

https://doi.org/10.2134/agronj2011.0212

33. Piao S, Ciais P, Huang Y, Shen Z, Peng S, Li J, Zhou L, Liu H, Ma Y, Ding Y, Friedlingstein P, Liu C, Tan K, Yu Y, Zhang T, Fang J (2010) The impacts of climate change on water resources and agriculture in China. Nature. https://doi.org/10.1038/nature09364

34. Porter JR, Xie L, Challinor AJ, Cochrane K, Howden SM, Iqbal MM, Lobell DB, Travasso MI, Aggarwal P, Hakala K, Jordan J (2015) Food security and food production systems, in: Climate Change 2014 Impacts, Adaptation and Vulnerability: Part A: Global and Sectoral Aspects. https://doi.org/10.1017/CBO9781107415379.012

35. Prasad PVV, Bheemanahalli R, Jagadish SVK (2017) Field crops and the fear of heat stressOpportunities, challenges and future directions. F Crop Res. https://doi.org/10.1016/j.fcr.2016.09.024

36. Pugh TAM, Müller C, Arneth A, Haverd V, Smith B (2016) Key knowledge and data gaps in modelling the influence of $\mathrm{CO} 2$ concentration on the terrestrial carbon sink. J Plant Physiol. https://doi.org/10.1016/j.jplph.2016.05.001

37. Ram H, Singh G, Mavi GS, Sohu VS (2012) Accumulated heat unit requirement and yield of irrigated wheat (Triticum aestivum L.). 14:147-153

38. Ramankutty N, Foley JA (1998) Characterizing patterns of global land use: An analysis of global croplands data. Global Biogeochem Cycles 12. https://doi.org/10.1029/98GB02512

39. Sacks WJ, Kucharik CJ (2011) Crop management and phenology trends in the U.S. Corn Belt: Impacts on yields, evapotranspiration and energy balance. Agric For Meteorol 151:882-894. https://doi.org/10.1016/j.agrformet.2011.02.010

40. Shahzad A, Ullah S, Dar AA, Sardar MF, Mehmood T, Tufail MA, Shakoor A, Haris M (2021) Nexus on climate change: agriculture and possible solution to cope future climate change stresses. Environ Sci Pollut Res 28:14211-14232. https://doi.org/10.1007/s11356-021-12649-8

41. Sikder S (1970) Accumulated Heat Unit and Phenology of Wheat Cultivars as Influenced by Late Sowing Heat Stress Condition. J Agric Rural Dev 7:59-64. https://doi.org/10.3329/jard.v7i1.4422

42. Solomon S, Qin D, Manning M, Chen Z, Marquis M, Averyt KB, Miller MT, Solomon HL, Qin S, Manning D, Chen M, Marquis Z, Averyt M, Tignor KB, Miller M (2007) H.L., Summary for Policymakers. In: Climate Change 2007: The Physical Science Basis. Contribution of Working Group I to the Fourth Assessment Report of the Intergovernmental Panel on Climate Change. D Qin M Manning Z Chen M Marquis K Averyt M Tignor HL Mill. New York Cambridge Univ. Press pp Geneva. https://doi.org/10.1038/446727a

43. Tao F, Zhang S, Zhang Z (2012) Spatiotemporal changes of wheat phenology in China under the effects of temperature, day length and cultivar thermal characteristics. Eur J Agron. https://doi.org/10.1016/j.eja.2012.07.005 
44. Tao F, Zhang Z, Liu J, Yokozawa M (2009) Modelling the impacts of weather and climate variability on crop productivity over a large area: A new super-ensemble-based probabilistic projection. Agric For Meteorol. https://doi.org/10.1016/j.agrformet.2009.02.015

45. Tao F, Zhang Z, Shi W, Liu Y, Xiao D, Zhang S, Zhu Z, Wang M, Liu F (2013) Single rice growth period was prolonged by cultivars shifts, but yield was damaged by climate change during 1981-2009 in China, and late rice was just opposite. Glob Chang Biol 19:3200-3209. https://doi.org/10.1111/gcb.12250

46. Tao F, Zhang Z, Xiao D, Zhang S, Rötter RP, Shi W, Liu Y, Wang M, Liu F, Zhang H (2014) Responses of wheat growth and yield to climate change in different climate zones of China, 1981-2009. Agric For Meteorol 189-190. https://doi.org/10.1016/j.agrformet.2014.01.013

47. Vanuytrecht E, Raes D, Willems P, Sam G (2012) Quantifying field-scale effects of elevated carbon dioxide concentration on crops. Clim Res 54. https://doi.org/10.3354/cr01096

48. White MA, Running SW, Thornton PE (1999) The impact of growing-season length variability on carbon assimilation and evapotranspiration over 88 years in the eastern US deciduous forest. Int $\mathrm{J}$ Biometeorol. https://doi.org/10.1007/s004840050097

49. Wu C, Gonsamo A, Chen JM, Kurz WA, Price DT, Lafleur PM, Jassal RS, Dragoni D, Bohrer G, Gough CM, Verma SB, Suyker AE, Munger JW (2012) Interannual and spatial impacts of phenological transitions, growing season length, and spring and autumn temperatures on carbon sequestration: $A$ North America flux data synthesis. Glob Planet Change. https://doi.org/10.1016/j.gloplacha.2012.05.021

50. Xin X, Wu T, Zhang J, Yao J, Fang Y (2020) Comparison of CMIP6 and CMIP5 simulations of precipitation in China and the East Asian summer monsoon. Int $\mathrm{J}$ Climatol 40. https://doi.org/10.1002/joc.6590

51. Xu C, Liu H, Williams AP, Yin Y, Wu X (2016) Trends toward an earlier peak of the growing season in Northern Hemisphere mid-latitudes. Glob Chang Biol 22:2852-2860. https://doi.org/10.1111/gcb.13224

52. Xu C, Wu W, Ge Q (2018) Impact assessment of climate change on rice yields using the ORYZA model in the Sichuan Basin, China. Int J Climatol 38:2922-2939. https://doi.org/10.1002/joc.5473

53. Yang X, Chen F, Lin X, Liu Z, Zhang H, Zhao J, Li K, Ye Q, Li Y, Lv S, Yang P, Wu W, Li Z, Lal R, Tang H (2015) Potential benefits of climate change for crop productivity in China. Agric For Meteorol. https://doi.org/10.1016/j.agrformet.2015.04.024

54. Yin Y, Deng H, Wu S (2019) Spatial-temporal variations in the thermal growing degree-days and season under climate warming in China during 1960-2011. Int J Biometeorol 63:649-658. https://doi.org/10.1007/s00484-017-1417-y

55. Zhang Z, Liu X, Wang P, Shuai J, Chen Y, Song X, Tao F (2014) The heat deficit index depicts the responses of rice yield to climate change in the northeastern three provinces of China. Reg Environ Chang 14. https://doi.org/10.1007/s10113-013-0479-6 
56. Zhao H, Dai T, Jing Q, Jiang D, Cao W (2007) Leaf senescence and grain filling affected by postanthesis high temperatures in two different wheat cultivars. Plant Growth Regul 51. https://doi.org/10.1007/s10725-006-9157-8

57. Zhao H, Fu YH, Wang X, Zhao C, Zeng Z, Piao S (2016) Timing of rice maturity in China is affected more by transplanting date than by climate change. Agric For Meteorol.

https://doi.org/10.1016/j.agrformet.2015.11.001

58. Zhou G, Wang Q (2018) A new nonlinear method for calculating growing degree days. Sci Rep 8:114. https://doi.org/10.1038/s41598-018-28392-z

59. Zhu W, Zheng Z, Jiang N, Zhang D (2018) A comparative analysis of the spatio-temporal variation in the phenologies of two herbaceous species and associated climatic driving factors on the Tibetan Plateau. Agric For Meteorol 248. https://doi.org/10.1016/j.agrformet.2017.09.021

\section{Figures}

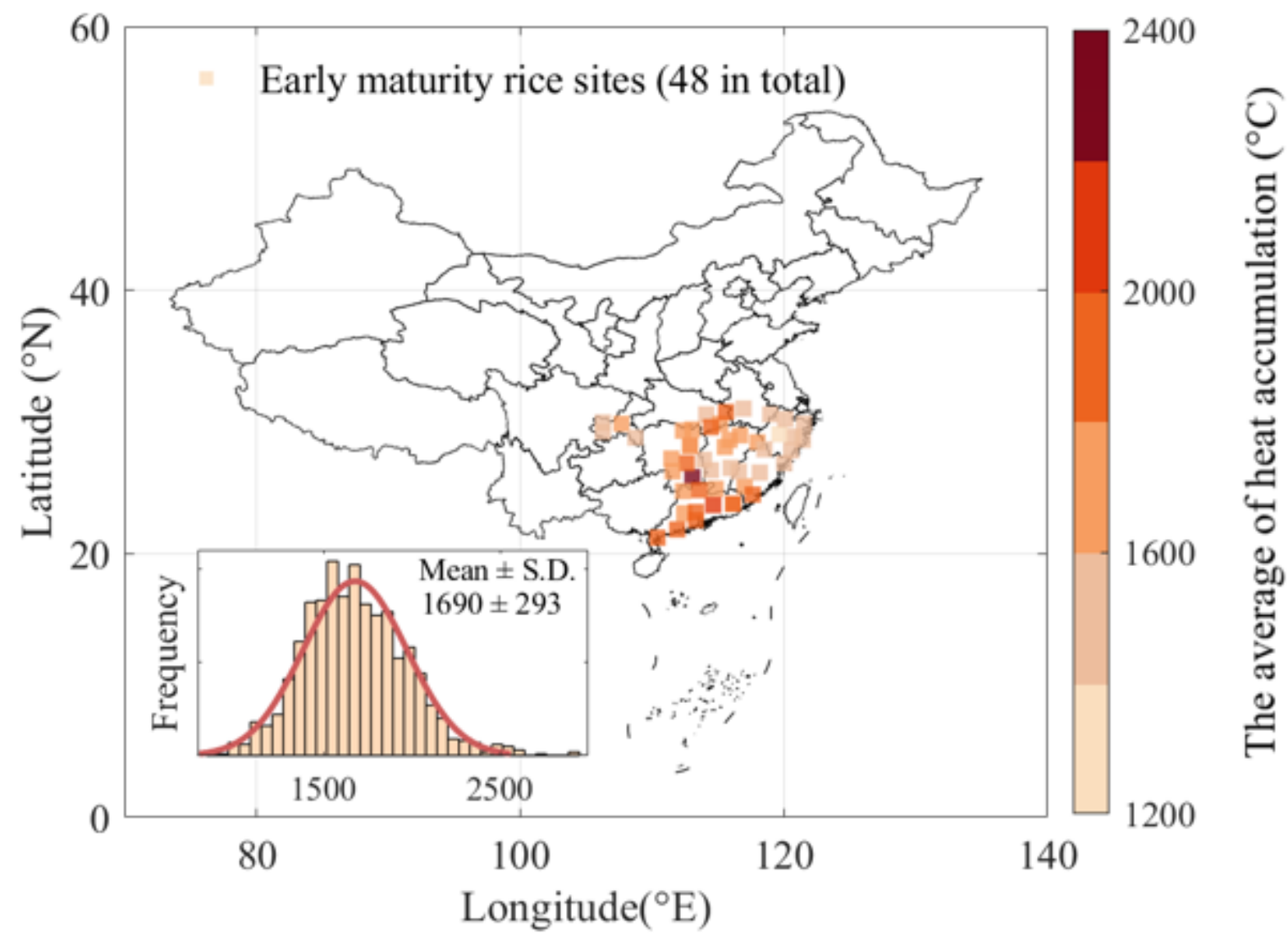

\section{Figure 1}

Distribution of early rice sites in China. 48 sites mainly distributed in the south China including 13 provinces were selected in this analysis. The density of color represented the average annual growing degree days (GDD) during whole growth period. The inner histogram reflected the frequency distribution of GDD across all sites during $1981-2010$. Mean \pm S.D. means the average \pm standard deviation of GDD. 

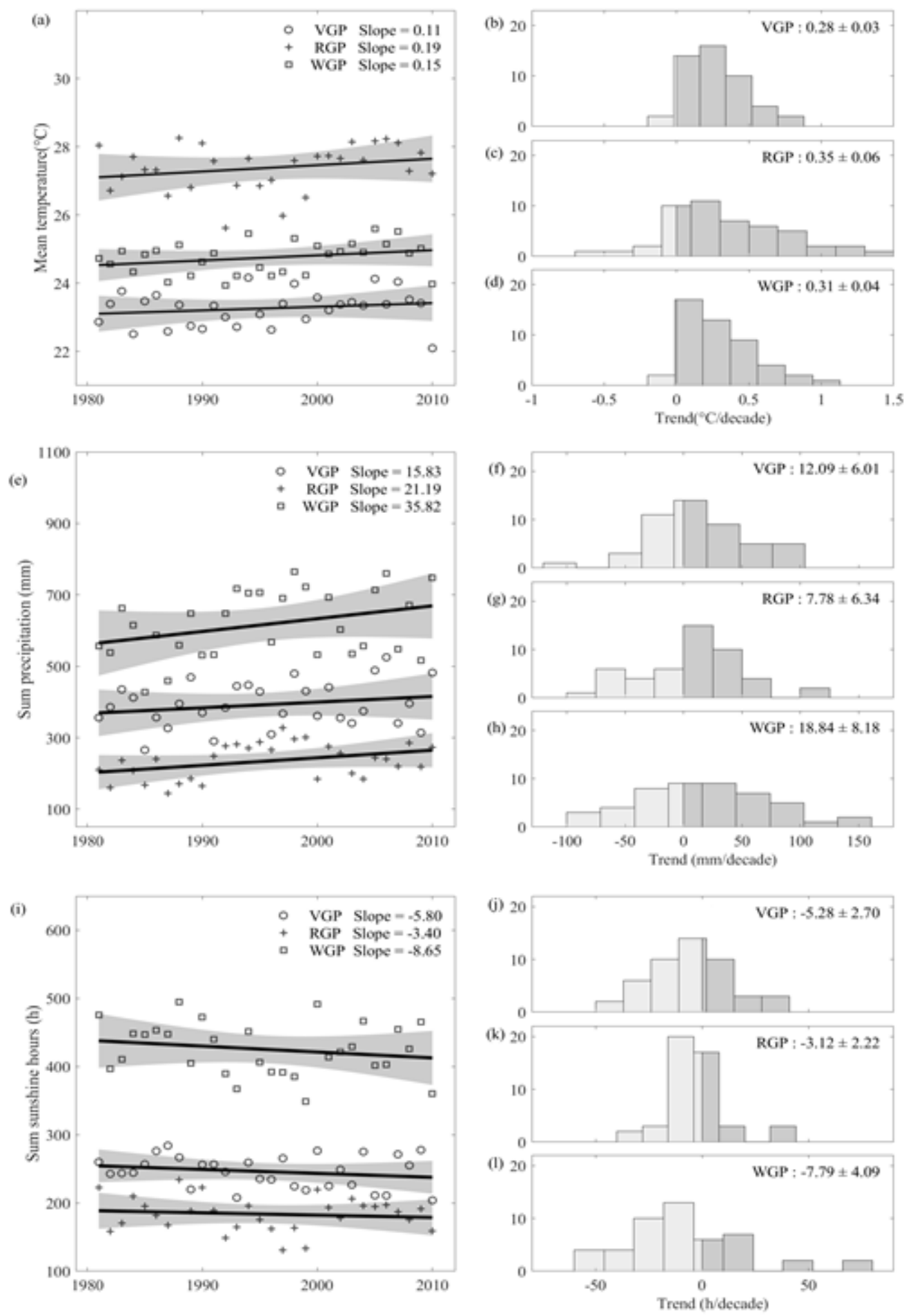

Figure 2

Temporal trends of climatic variables. (a) to (d) Changes of mean temperature across all sites during vegetative growth period (VGP), reproductive growth period (RGP) and whole growth period (WGP). (e) to (h) Changes of accumulative precipitation across all sites during VGP, RGP and WGP. (i) to (I) Changes of accumulative sunshine hours across all sites during VGP, RGP and WGP. Blue blocks in the histogram indicate negative trends, while red blocks report positive trends. The mean value, standard error and the percentages of significant trends $(P<0.05)$ are shown in each histogram panel. 
(a)

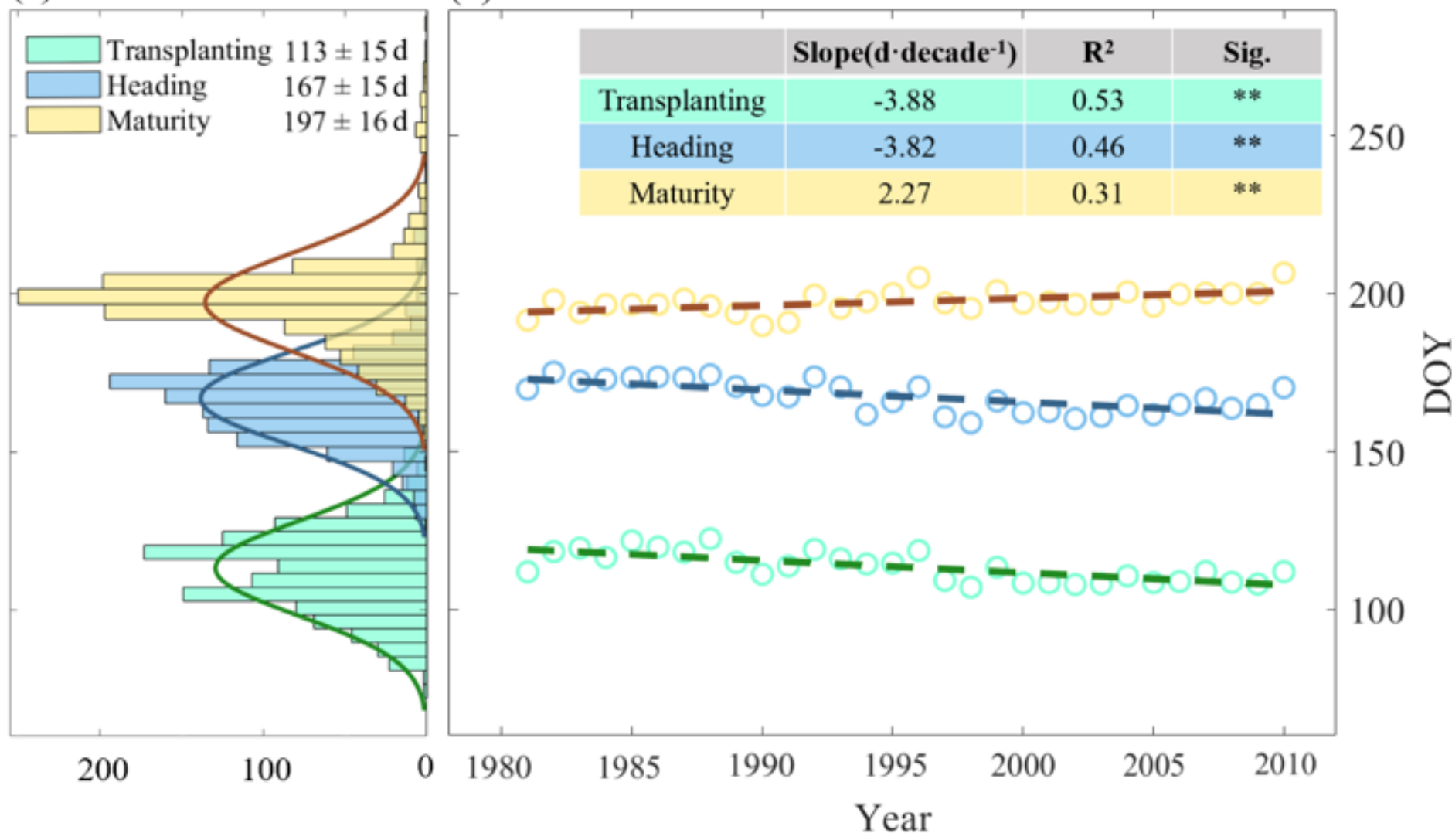

Figure 3

Characteristics of phenological events. (a) Histogram of phenological documents (i.e., date of transplanting, heading and maturity) during 1981 - 2010. (b) Temporal distribution of transplanting, heading and maturity, respectively. Frequency histogram (a) showed the average value of the dates of transplanting, heading and maturity during the study period. Color circles in (b) represent yearly mean phenological dates across all sites. 

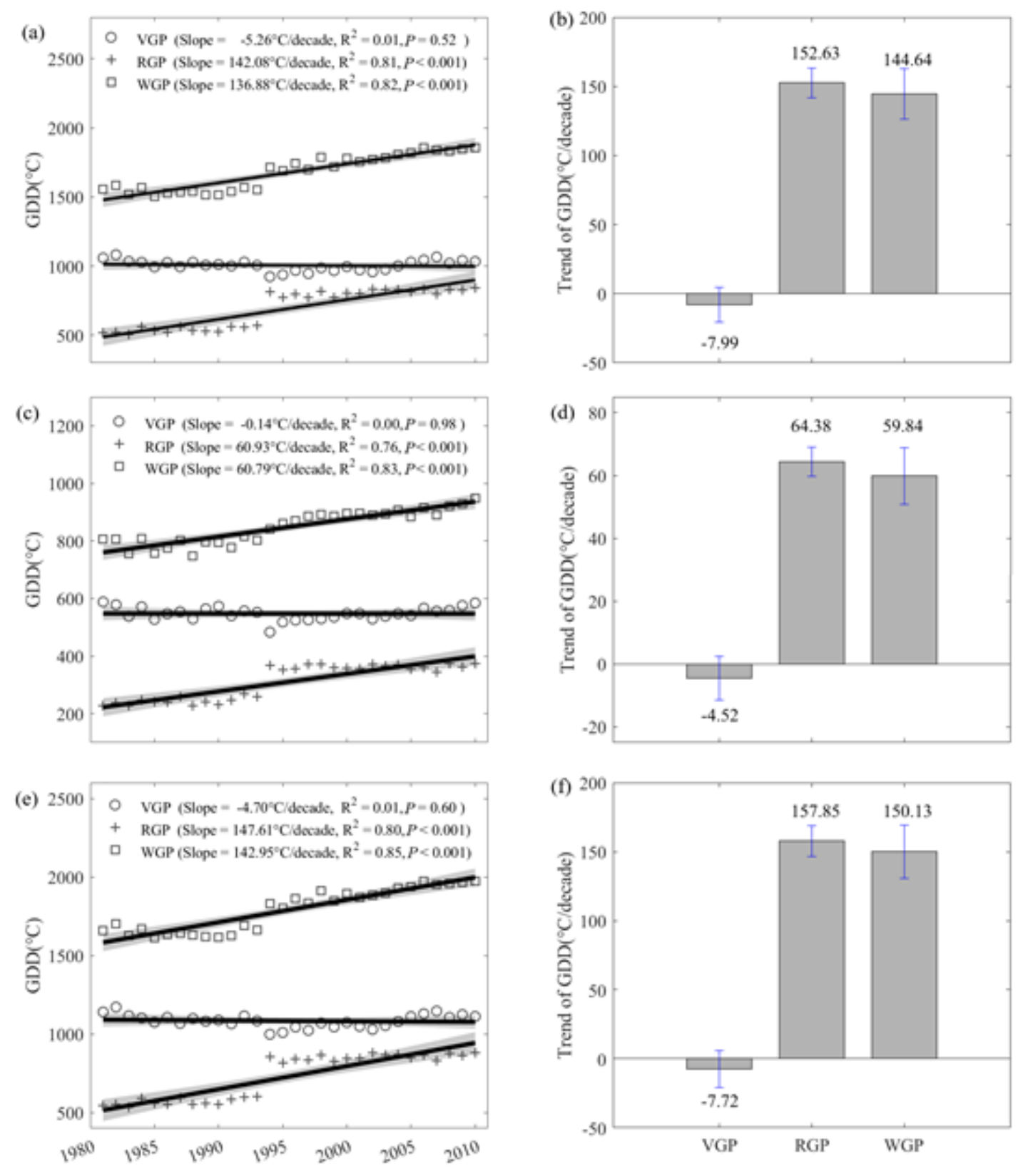

\section{Figure 4}

Trends of growing degree days (GDD) during the three growth periods, i.e. vegetative growth period (VGP), reproductive growth period (RGP) and whole growth period (WGP) using three methods in GDD estimation ( $a, c$ and $e$ ). Different shapes represent the mean GDD values across all sites during VGP, RGP and WGP, respectively. (b, $\mathbf{d}$ and $\mathbf{f}$ ) The average trends of GDD across all sites during the study periods. 


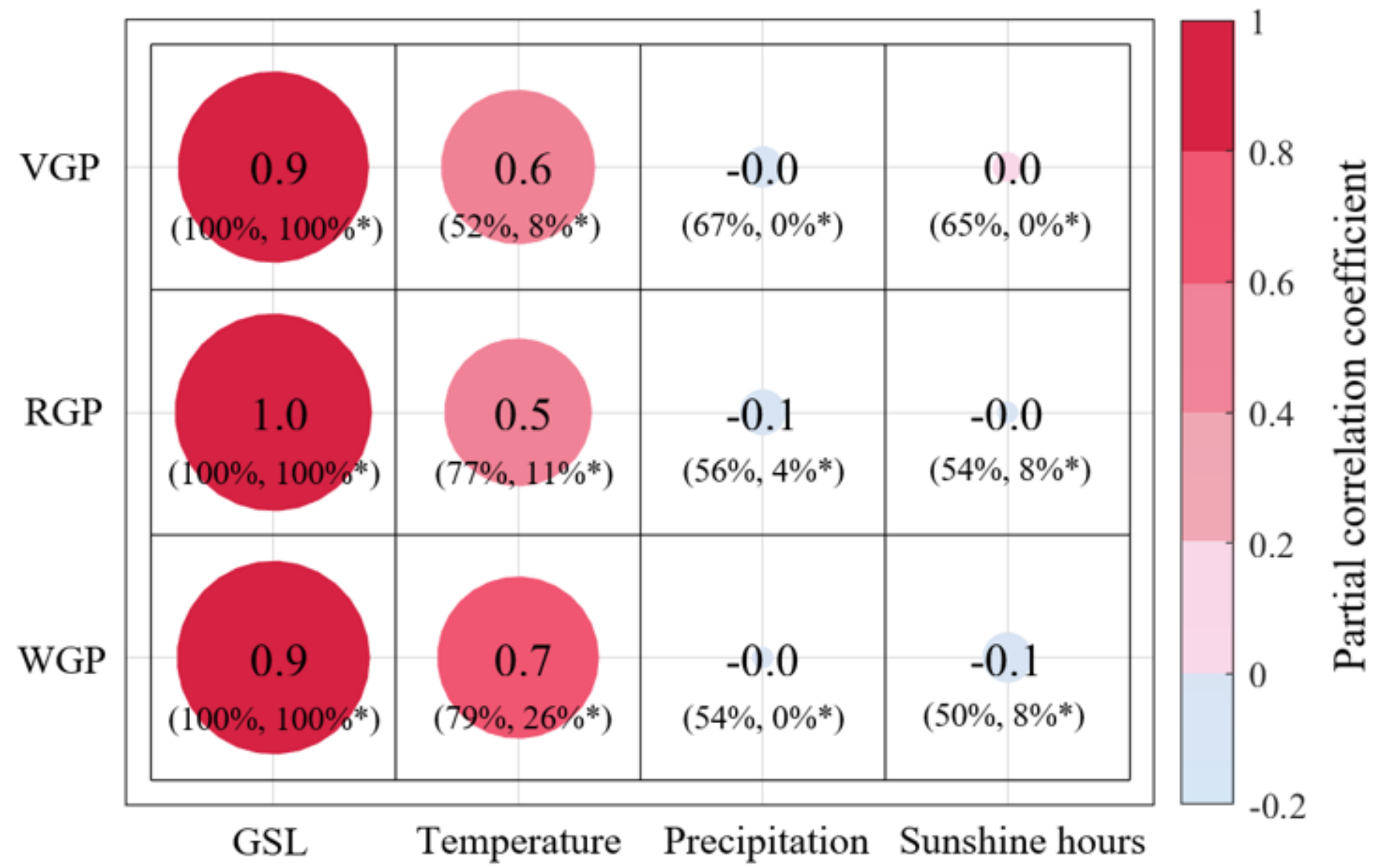

Figure 5

The average of partial correlation coefficients between growing degree days (GDD) and growing season length (GSL) or climatic factors (mean temperature, cumulative precipitation, cumulative sunshine hours) across early rice sites during each of the growth periods, i.e. vegetative growth period (VGP), reproductive growth period (RGP) and whole growth period (WGP). Colors and the size of blocks represent the values of partial correlation coefficients as indicated in the color bar on the right side. Values in the brackets represent the percentage of the coefficients with the same direction as the average value across all sites and the proportion of significant correlations.

\section{Supplementary Files}

This is a list of supplementary files associated with this preprint. Click to download.

- Appendices.docx 